\title{
NEOCLYSTOPSENELLA (BETHYLIDAE) A SYNONYM OF TAPINOMA (FORMICIDAE)
}

\author{
By William L. Brown, JR. \\ Department of Entomology \\ Cornell University \\ Ithaca, NY 14853
}

I followed up Dr. Karl Krombein's suggestion that Kurian's species Neoclystopsenella luffae might be an ant, and not a bethylid as originally described. The type place of deposit is unknown, but a reading of the original paper convinces me that the description, although vague and incomplete, fits well the current concept of male Tapinoma in the subfamily Dolichoderinae. The specific identity of Tapinoma luffae NEW COMBINATION remains obscure, but judging from the small size given, " $2.4 \mathrm{~mm}$," and the wing venation as figured by Kurian, it may be close to or the same as T. melanocephalum or one of its relatives in "subgenus Micromyrma."

\section{Tapinoma}

Tapinoma Foerster, 1850: 43, worker, queen (not male). Type: Tapinoma collina Foerster $=$ Tapinoma erraticum, monobasic.

Neoclystopsenella Kurian 1955: 133, male. Type: Neoclystopsenella luffae Kurian, by original designation, monobasic (described in Bethylidae). New synonym.

\section{Reference Cited}

Foerster, A. 1850. Hymenopterologische Studien. 1. Formicariae, pp. 1-74. Verlag E. Ter Meer, Aachen.

Kurian, C. 1955. Bethyloidea (Hymenoptera) from India. Agra University Journal of Research (Science) 4: 67-155. 

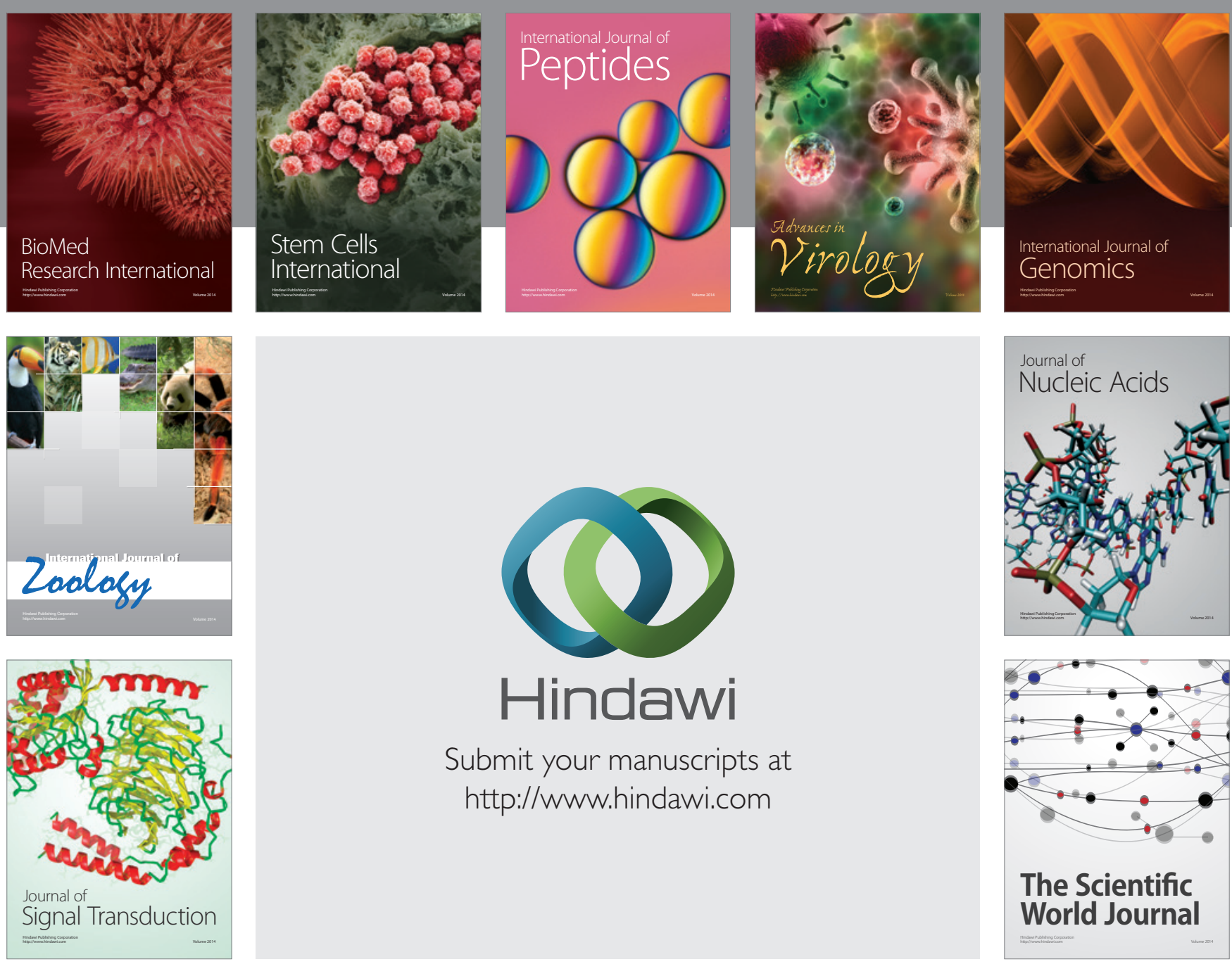

Submit your manuscripts at

http://www.hindawi.com
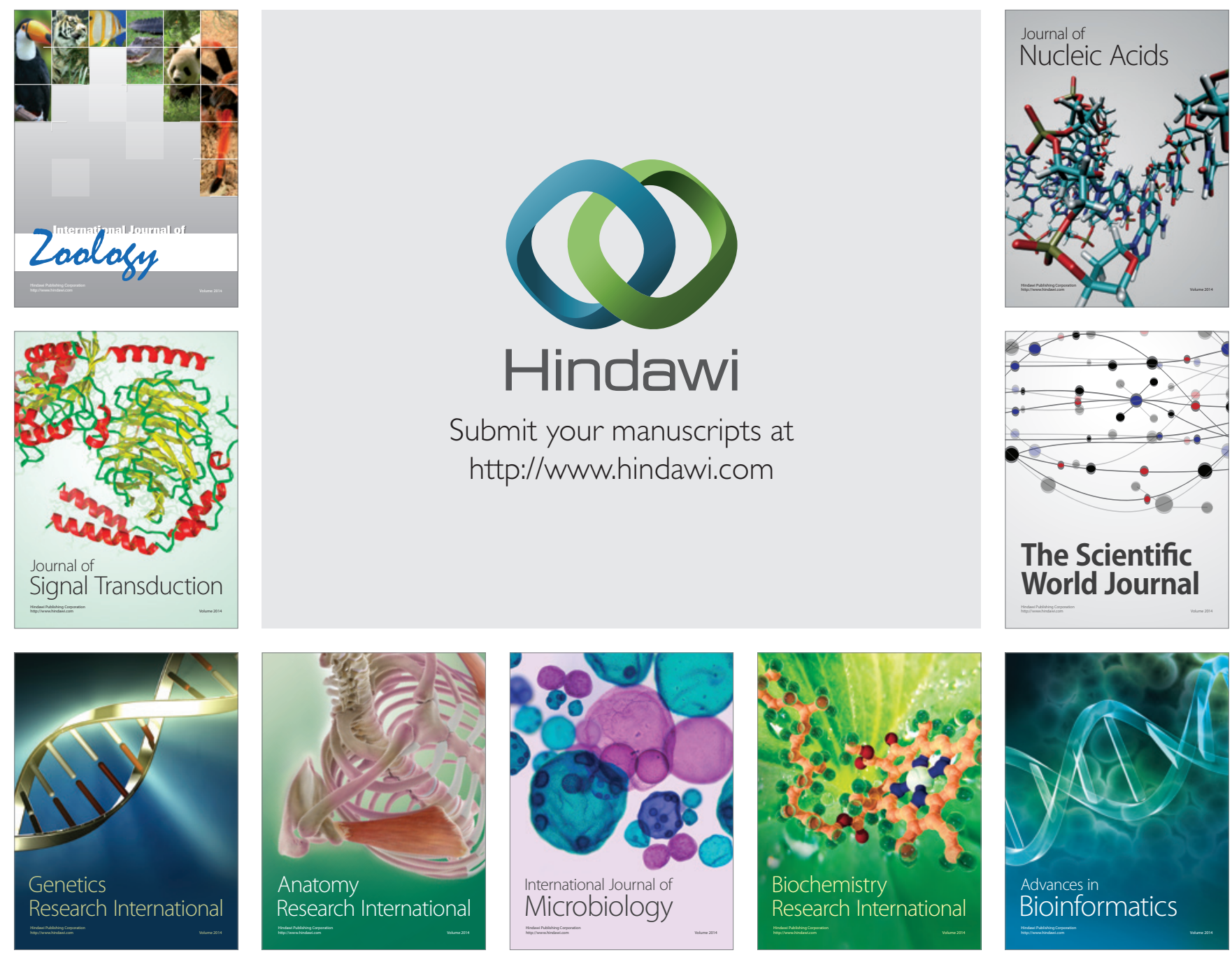

The Scientific World Journal
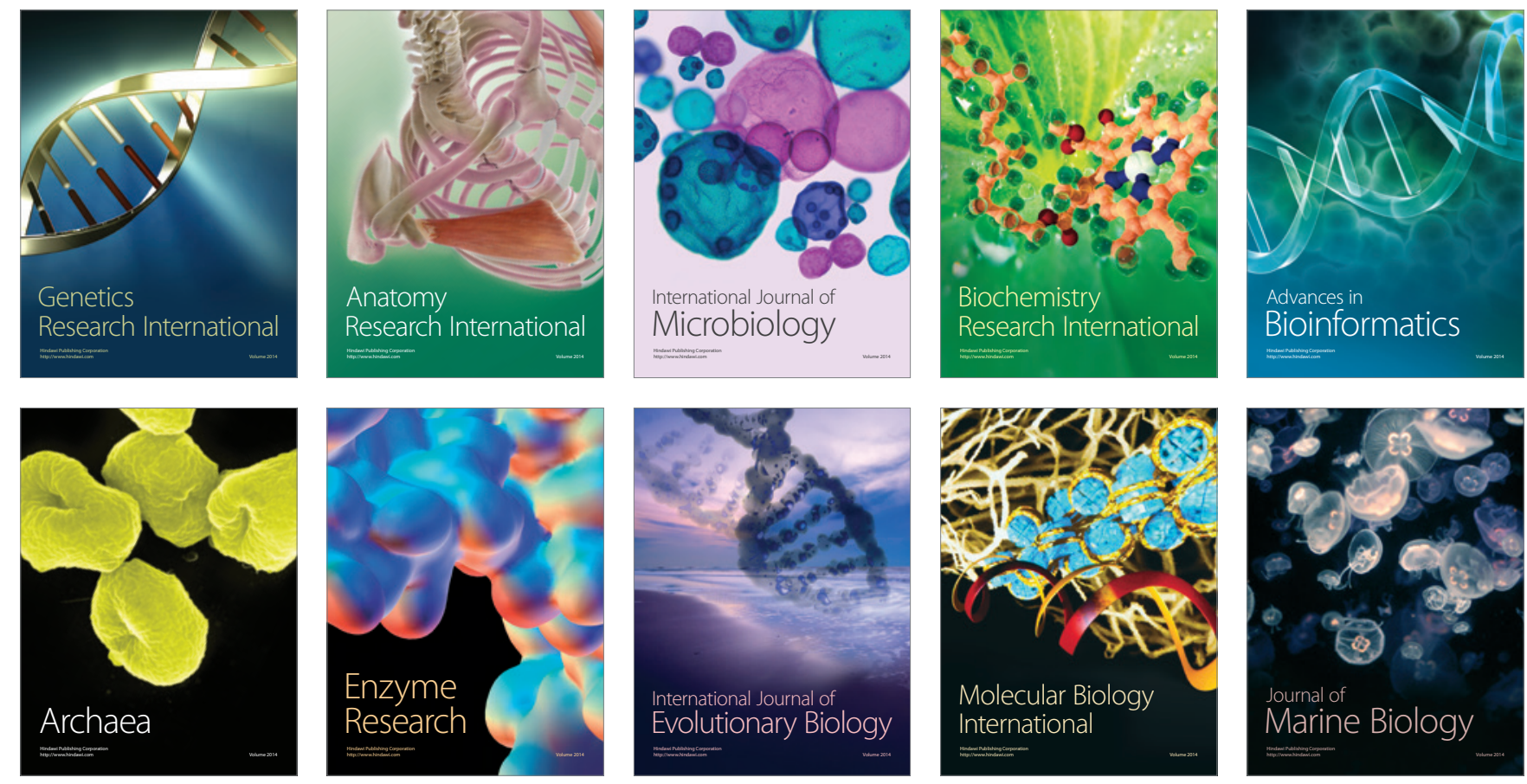